\title{
Medicolegal audit in the West Midlands region: analysis of 100 cases
}

\author{
CLIFFORD HAWKINS, IAN PATERSON
}

\begin{abstract}
One hundred medicolegal cases were analysed to obtain quantitative data about diagnoses and the causes of litigation that affect hospital doctors in the National Health Service. Sixteen actions concerned minor problems that are an unavoidable risk of treatment, and 39 were due to natural causes. In other cases it was debatable whether a medical accident or negligence was responsible. At the end of three years 73 actions had been withdrawn, 12 settled out of court, and one lost in court by the plaintiff, and 14 were pending. Of these 14, nine were likely to reach court on charges of negligence. Contributory causes were failure of communication in 27 and matters connected with the patient's attitude or personality in 20.

Because much time and money are spent on cases that should never have started a doctor should sit on the legal aid panel to give advice for medical cases. Also, solicitors should obtain an independent medical opinion when a complaint is first received from a patient. Consent forms should be more informative and give details of what can reasonably be expected from treatment and its possible risks.
\end{abstract}

\section{Introduction}

Medicolegal matters published in daily newspapers and medical journals describe disasters or new legal decisions. These reports give a selected view and thus no idea of the ordinary range of cases either when they first occur or of their outcome. Facts have long been needed,,$^{12}$ and the regional solicitor's office is a source of material for study because nearly all notifications and firm allegations-which usually include a writ or letter from the patient's solicitor-are first directed there (owing to the vicarious liability of the health authority). Therefore it was possible to obtain quantitative data about the reasons for legal actions and about causes that contribute to confrontations between doctors and patients. It was thought that this information might lead to suggestions for preventing some cases arising.

\section{Materials and methods}

One hundred files were taken at random from the total of 324 medicolegal cases that occurred during 1984. All of the cases came from hospitals in the West Midlands region, which is the largest of the National Health Service

Postgraduate Medical Centre, Birmingham B15 2TQ

CLIFFORD HAWKINS, MD, FRCP, honorary consultant physician

Regional Health Authority, Birmingham B16 9PA

IAN PATERSON, LLB, MBIM, regional solicitor

Correspondence to: Dr Hawkins. regions in England. The region has a population of 5256000 people, 211 hospitals, a hospital medical staff of 5850 (1512 consultant and 4338 other staff such as training grades), and a yearly workload of roughly 600000 inpatients and over 5 million outpatient attendances. ${ }^{3}$ The year 1984 was selected because a convenient method of recording and retrieving cases started at that time, and because a period of three years would allow time for the result to be determined in most cases. All the patients whose cases were studied had been NHS hospital patients, and none was then under the direct care of his or her general practitioner.

Each file was studied sequentially starting with the first letter from the patient's solicitor. The diagnosis of the complaint was noted and the person (or persons) responsible was as far as possible ascertained. This was occasionally difficult as some mishaps are due to no single cause, and the damages awarded have to be shared between the Medical Defence Union or Medical Protection Society and the health authority.

The legal outcome was assessed: some actions had been withdrawn; others were unlikely to continue and were presumed dropped when nothing had been heard from solicitors after 18 months (this would not invariably be correct as the statutory limitation period is three years, and the further time limit of service had not expired). Inevitably some cases were still pending at the end of the three year period because no legal deadline exists, and litigation may even continue for 10 years before coming to court.

Allegations were also classified as follows: an unavoidable risk of treatment, complication due to natural causes, and medical accident or negligence. But the last was difficult to classify as the cause of many cases was debatable, and this is one reason why legal processes can take so long. Data were also collected concerning the personality of the patients, especially when claims were unexpected or seemed unjustified, and details about problems caused by failures of communication were noted. Particular attention was given to precipitating factors and to possible ways of preventing unnecessary actions.

\section{Results}

Cases were classified partly under specialties and partly under problems such as missed fractures (table I) as these usually occur in the accident and emergency department when the patient is seen by junior staff. Table I gives the distribution of actions and their outcome. Surgical cases headed the list, but most of these were later withdrawn.

Surgical cases-Twelve cases were the result of relatively minor problems which are usually unavoidable, such as infection of the surgical wound that responded to an antibiotic and left no permanent damage, a reaction to a nylon suture, or dissatisfaction with scars. Eleven were due to alleged complications of surgery or complaints about the result, and three deaths occurred but all were in ill patients where mortality is expected: one had a severe haematemesis and two patients had a prostatectomy. Gangrene of the leg was mistakenly thought by two patients to be due to minor operations on the feet. Perforation of the colon during colonoscopy resulted in a temporary colostomy in one patient, and a woman fell off the operating table (fortunately suffering no permanent injury). A wrong operation was due to the removal of the wrong exostosis from a woman's foot and a second operation was needed to remove the one on the lateral malleolus.

Medical problems-There were 15 actions against physicians. Two were alleged failures of diagnosis: one concerned diabetes mellitus and the other complaint was from a businessman who claimed that if the diagnosis of motor neurone disease had been made earlier he could have arranged his affairs appropriately. One case was about a man who died after a percutaneous needle liver biopsy had been performed without explanation 
or consent. Five concerned drugs: a woman complained about a depressed scar (due to subcutaneous fat atrophy) which followed an injection of methylprednisolone and a local anaesthetic for pain in the neck; one was a claim that brain and nerve damage was due to treatment for eczema in 1966; vincristine caused peripheral neuropathy in a man with malignant disease (he recovered and the case was dropped); a laparotomy was claimed to have been unnecessary as the jaundice was probably induced by drugs, and there was nearly a disaster when an infant was prescribed $0.8 \mathrm{mg}$ papaveretum after an operation for pyloric stenosis but the nurse measured $8 \mathrm{mg}$ in the syringe instead, although fortunately she recognised the mistake before the full dose had been given, and the respiratory arrest was treated successfully. The parents, however, started an action "to prevent it happening to another child" but dropped it after a letter of apology and a description of measures taken to prevent it recurring was sent to them. (These were special paediatric diluted ampoules and undoubtedly the importance of writing 800 micrograms and not $0.8 \mathrm{mg}$ was emphasised). Five deaths were the subject of litigation but were due to natural causes, and the cases were withdrawn. Two claims were for brain damage due to vaccination against pertussis.

TABLE I-Analysis of 100 medicolegal cases and their outcome three years later

\begin{tabular}{lcccc}
\hline Diagnosis & $\begin{array}{c}\text { No of } \\
\text { patients }\end{array}$ & $\begin{array}{c}\text { No of cases } \\
\text { withdrawn }\end{array}$ & $\begin{array}{c}\text { No of cases } \\
\text { settled }\end{array}$ & $\begin{array}{c}\text { No of cases } \\
\text { pending }\end{array}$ \\
\hline Surgical & 31 & 28 & 3 & - \\
Medical & 15 & 11 & 1 & 3 \\
Obstetric/gynaecological & 10 & 7 & - & 3 \\
Orthopaedic & 9 & 7 & 2 & - \\
Failed sterilisation & $8^{\star}$ & 4 & 3 & - \\
Failed vasectomy & 2 & 1 & - & 1 \\
Anaesthetic & 7 & 5 & - & 2 \\
Missed fracture & 6 & 3 & 2 & 1 \\
Birth injury & 4 & 1 & - & 3 \\
Ophthalmic & 4 & 4 & - & - \\
Dental & 3 & 1 & 1 & 1 \\
Radiological & 1 & 1 & - & - \\
& & & & \\
\hline
\end{tabular}

‡One case of failed sterilisation was lost by the plaintiff in a court case. a possible pressure lesion on the buttock. A man died after being given intrathecal morphine.

Miscellaneous problems-All four ophthalmic cases were due either to natural causes or to an unavoidable complication of an operation and were dropped. The dental actions were: a dental bridge was broken during recovery from an anaesthetic when the man bit an airway (payment sufficien to cover the cost of replacement satisfied him) and another followed inhalation of a dental filling, which was recognised and retrieved promptly by bronchoscopy; but a small boy who suddenly struggled during an extraction and inhaled a tooth needed a temporary tracheotomy. Finally, there was an action against a radiologist because of a possible reaction from a Discogram injection in a patient with a prolapsed cervical disc.

\section{PRECIPITATING FACTORS}

The possibility of finding factors that precipitated litigation (especially minor or even trivial ones) such as awkward patients or difficult doctors was limited because of inadequate hospital case records: a note might be made if the patient was difficult but no mention made if the doctor was arrogant or did not talk. The label "difficult patient," which seemed likely in 20 cases, did not imply a deliberate intention and included a child who would not let the doctor examine him properly as well as patients who sometimes justified a description of hypochondriasis because of their multiple unexplainable symptoms and low pain threshold.

Problems connected with communication occurred in 27 actions. Poor doctor-patient communication was noted in 16 of these and was sometimes apparent when reading the hospital records but more often became obvious when the matter was in the hands of lawyers. Alleged statements by doctors triggered off six actions. For example, one doctor was alleged to have told a patient that the operation might not have been done properly, although he knew nothing about the original surgery (the woman was suffering from pain after appendicectomy). Insufficient postoperation instructions were blamed as being partly responsible for the deaths of two patients; and one case arose when an elderly woman developed a stroke 48 hours after recovering from the anaesthetic given for a cholecystectomy as a nurse suggested to the woman's husband that she might have been given too much anaesthetic-an example of a case started by a tactless and erroneous remark.

TABLE II-Cases that have been settled

Obstetrics and gynaecological-The 10 cases (apart from actions for failed sterilisation) were as follows: three were due to nylon sutures; two to dissatisfaction with treatment (one patient alleged that it caused an abortion); two cases of ruptured uterus were reported-one happened during a dilatation and curettage for retained products, and the other complaint was that the surgeon performed a hysterectomy without consent when dealing with the rupture which occurred during delivery in a woman who had previously had a caesarean section. Perforations had occurred in two patients during laparoscopy, and in another the bladder had been perforated during a hysterectomy.

Actions against orthopaedic surgeons-One instance of wound infection; three complaints of poor results of treatment of fractures-a stiff fifth finger after a fractured phalanx, non-union of the ulnar, and pain following an os calcis fracture. One action concerned alleged wrong diagnosis of a swollen knee, and another was due to a pressure paralysis of the radial nerve being missed in a child of 3 years - examination was difficult because of screaming and radiographs failed to show a dislocation of the head of the radius which complicated a fractured proximal ulnar bone. Two patients were dissatisfied with an operation on the feet and the last case happened when the tibia was fractured when the plate used to hold in place the original fracture was being removed.

Missed fractures-There were three missed fractures in fingers, two of the scaphoid bone (in one the delay in detecting it on the $x$ ray film was only two weeks) and a possible avulsion fracture of the lateral malleolus of the ankle.

Unwanted pregnancy - These actions were all connected with failure to obtain informed consent. This was often disputed, but the defence was weakened when possible failure (of tubal sterilisation or vasectomy) was not mentioned on the consent form or a record of counselling written in the case notes. There were four allegations of injury to the neonate from childbirth: one was of Erb's palsy, and the others were cases of brain damage, the problem in each of these being whether the cause was congenital or traumatic.

Anaesthetic cases-The seven actions were as follows: a boy with asthma died under anaesthesia during an operation for antral washout, and necropsy showed that death was due to bilateral pneumothoraces; two children (one had Marfan's syndrome) allegedly suffered brain damage because of collapse under anaesthesia, and one elderly woman had a stroke after an operation; two complaints followed epidural anaesthesia - a man collapsed afterwards (this was apparently psychogenic) and a woman started an action because of
Patient fell off operating table

Wrong operation (wrong exostosis on foot removed)

Glass missed in wound

Needle liver biopsy without consent

Failed sterilisation (three cases)

Damage to dental bridge

Missed fracture of 5 th metacarpal bone

Delay of two weeks in diagnosing fracture of scaphoid bone

Tibia fractured when plate was removed

Misdiagnosis of knee

TABLE III-Fourteen cases pending at the end of three years and likely to be settled, go to court, or be withdrawn

Problems and allegations were as follows:

Child inhaled tooth during dental extraction

Brain damage during childbirth (three cases)

Brain damage in infants from collapse under anaesthesia (two cases)

Erb's palsy due to difficult confinement

Brain damage from vaccination against pertussis (two cases)

Injury to artery during operation on prolapsed lumbar disc

Perforation of bladder during hysterectomy

Perforation of bladder during hyster

Fractured finger

Fractured finger

$$
\text { Failed vasectomy }
$$

At the end of three years 73 actions had been withdrawn. Of these, 16 complaints seemed to be minor and an unavoidable complication of treatment, and 39 would generally have been considered as due to natural causes and not to any misdeed of the doctor. Twelve cases-where the charge of negligence could not be denied-had been settled out of court (table II) and 14 were pending (table III), nine of which could go to court. The plaintiff in one case of failed sterilisation lost in court; otherwise no case had yet reached court.

\section{SEQUEL AFTER THREE YEARS}




\section{Discussion}

A striking impression from this study was the amount of time, money, and trouble that is spent on medicolegal matters, for even a case that is apparently straightforward can generate an avalanche of correspondence. This begins when a patient approaches a solicitor with a complaint and the solicitor writes to the local hospital or district health authority asking to see the medical case notes but without mentioning the reason for this; the letter is referred to the regional health authority's solicitor, who often has to proceed with correspondence about release of the records. Sometimes details of the complaint are given, but often the plaintiff's solicitor refuses to do so, and thereafter a series of tactical delaying letters are sent and secrecy maintained. The regional health authority's solicitor then receives a summons for disclosure-usually supported by legal aid-if he or she still refuses to release the records.

This is only the beginning of the saga: for thereafter and after the service of writ and statement of claim the various doctors in the case have to be traced (some may have left the United Kingdom) and their defence society discovered and written to, and the doctors have to respond to all the allegations if known. Then the defence body (Medical Defence Union or Medical Protection Society) starts an investigation and seeks the opinion of experts, who will also advise on liability and the possible involvement of non-medical staff; the latter have to be traced and respond, and the regional health authority (responsible for these) seeks further reports from experts.

Many claims seem hardly to justify such an endeavour that may result in a file containing 100 letters and 126 pages of writing before the case is withdrawn. For example, one file of this size concerned a small scar on a woman's buttock-a coloured photograph with a 10 pence piece beside it illustrated its diminutive nature-which apparently resulted from a pressure sore contracted when an epidural anaesthetic was given to relieve pain during the successful delivery of a healthy child. Another file recounted the tale of a fracture that had been missed as no radiograph had been taken when the man first attended the accident and emergency department, yet the fracture of a finger, which was minimal and not displaced, needed no treatment apart from that already given. Such cases direct attention and energy from more deserving ones. The apparent ease for obtaining legal aid for trivial cases is surprising. A private solicitor obviously has a financial incentive for taking up such a case, but for doctors, nurses, and the medical defence bodies it is a waste of time, as it is for the health authority's full time solicitor.

The reason why so many actions $(73 \%)$ were withdrawn was sometimes because the report of an independent expert indicated that the condition was due to natural causes (39\% in this series) or an unavoidable risk, and it is unfortunate that some patients may find out for the first time during legal proceedings the nature of the problem. One cause for the delay in dealing with cases was that so many cases were debatable and lay in a grey area, where it was difficult to decide whether negligence had occurred or whether it was a medical accident-a mishap instead of malpractice. Occasional medical accidents are inevitable, and that most are not the result of negligence is an opinion given by the Association for the Victims of Medical Accidents. ${ }^{4}$

\section{Contributory causes}

These results add hard data to the excellent publications of the Medical Defence Union and Medical Protection Society, which guide doctors about avoiding litigation. It has been emphasised that actions are often triggered by a set of circumstances: an off hand receptionist, unsympathetic handling by doctors and nurses, mislaid case notes, the frustrations of patients perhaps due to hours spent waiting to see the doctor, and poor communication such as doctors who do not talk or fail to communicate with each other so that letters or reports of $x$ ray examinations are not received.

It would be easy to assume that the rise in the number of actions is merely due to the public becoming litigation minded-hardly surprising in view of the financial advantage of suing doctors as advertised by the media in spotlighting fantastic awards, but the problem is more complex, and the various reasons for patientdoctor confrontations have been described in detail elsewhere. ${ }^{5}$ For example, some unexpected and apparently trivial approaches to lawyers are due to social or psychological reasons rather than alleged failure of medical care; and some underlying causes of complaints are caused by a failure to communicate after a bad or tragic result or from resentment because the doctor seemed too busy to talk; and sometimes bereaved relatives have feelings of guilt and absolve themselves by blaming the doctor. Information obtained from the case files of these 100 patients indicated the following contributory causes.

\section{Bad handling of patients}

Statements were recorded in the investigation of claims such as "arrogant and offhand consultant" and "an unsympathetic, abrupt, and unhelpful ward sister"; and a child whose cut would not heal was apparently told by an "extremely offhand nurse" not to make such a fuss, but later a large piece of glass was removed under an anaesthetic. The importance of a good rapport with the patient was illustrated when a man who was inflicted with a temporary colostomy because his colon was perforated during colonoscopy decided to drop his action after a sympathetic talk with his surgeon but later restarted it when he was seen by a junior doctor at the outpatient clinic instead of receiving the special attention of his surgeon.

\section{Problem patients}

Eight of the "difficult" patients appeared to have a low pain threshold or hypochondriasis. For example, a nurse who had had several unnecessary operations including a laparotomy which showed no abnormality was dissatisfied with her gynaecological treatment, and a woman who had had a normal gall bladder removed because of unexplained pain complained of severe pain afterwards which was associated with an unabsorbed nylon stitch. It is hazardous for surgeons to be driven into what they consider to be an unnecessary operation either for doubtful cosmetic reasons or because of the constant complaint of pain: a young woman insisted against the advice of the surgeon on the removal of a keloid scar which followed BCG vaccination and sued the surgeon because of the new keloid scar caused by his incision. More tragic was the case of a woman with multiple symptoms who had had many investigations performed-the results of which were normalbecause of continuous abdominal pain which finally drove the gynaecologist to perform a laparoscopy, and she died due to a perforated viscus. Some patients need psychiatric help and not the surgeon's knife.

\section{Failure of communication}

"One of the reasons for the growth in litigation is failure by doctors and nurses to keep patients fully informed of what is happening," and this has been emphasised by both of the medical defence bodies. That most patients simply want an explanation is also the experience of the Patients' Association (personal communication) and the Association for the Victims of Medical Accidents ${ }^{4}$ - and saying sorry is not admitting liability. ${ }^{7}$ Yet it was difficult to find data in this series of cases to support the belief that explaining would be sufficient in most cases. This may have been because, although case notes are full of information about fluid and electrolyte balance, bowel actions, sleeping problems, and so on, little or nothing is recorded about what has been told to the patient, except occasionally when a problem sheet is used with a section for this (figure) ${ }^{8}$ or the consultant has a special interest in this aspect.

Nevertheless, failure of doctor-patient communication occurred in 16 instances. For example, the failure to obtain consent before a 
liver biopsy was carried out, and there was no record in the hospital notes or on the consent forms that possible failure had been mentioned in cases of failed vasectomy and sterilisation, although the surgeons were convinced that they had told the patients. Inadequate case records were undoubtedly a cause for failure of the doctor's defence and are a bane for solicitors when, as in one case, one lot of notes arrived at the regional health authority's solicitor's office "out of order and pages torn or missing."

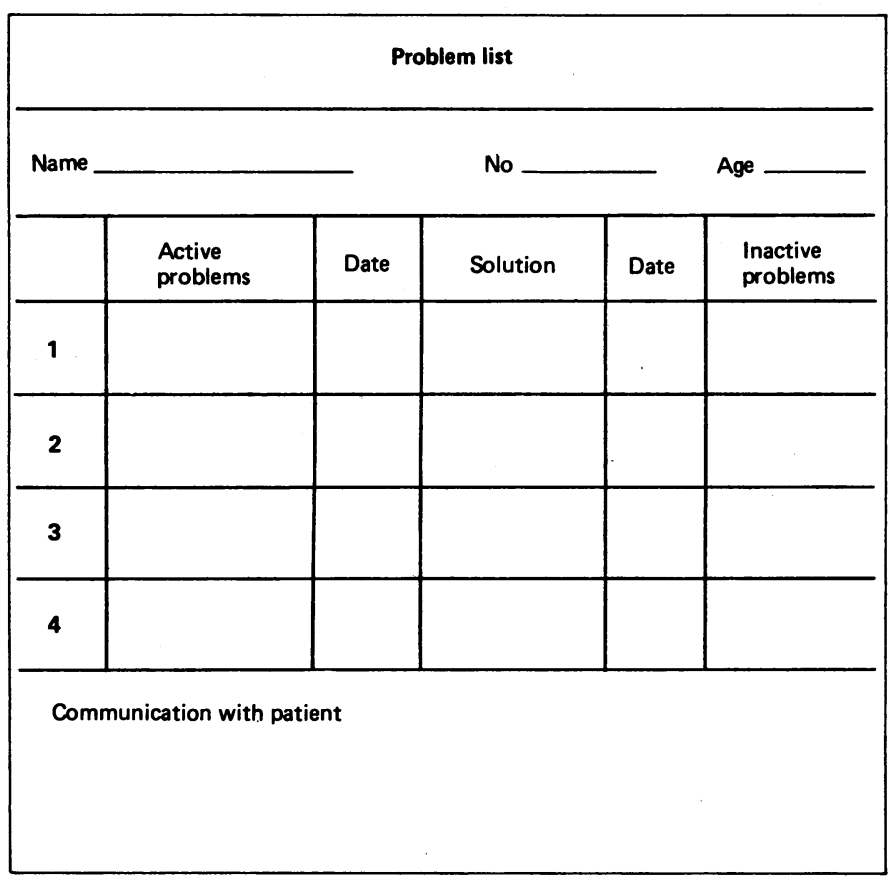

Problem sheet for consultations with patients.

\section{Suggestions for preventing unnecessary litigations}

The frustrations of patients and worries of doctors might be avoided if a middle way was found that was conciliatory and not confrontational. Also, stopping non-runners at the start would save public money as legal aid is so of ten provided for fruitless cases. The following measures are suggested:

(1) A doctor should sit on the legal aid panel to clarify medical issues arising out of or omissions from medical reports supportive of the applicant. Then cases that are obviously due to natural causes or to an inherent risk of treatment can be excluded and abortive expenditure on unnecessary actions avoided. An advantage of the contingency fee system in the United States is that lawyers obtain a medical opinion at the start, instead of later during the entrenched position of conflict, because they only accept claims that are supported by the law firm's medical advisers and are likely to yield sufficient damages to justify their firm's investment in a lawsuit. ${ }^{9}$ In one survey $99 \%$ of plaintiff's lawyers reported that they would not proceed with the case unless a medical evaluation from a consulted physician supported both negligence and a causal relation. ${ }^{10}$

(2) As a doctor does not sit on the legal aid panel at present an independent medical opinion should be obtained by the plaintiff's solicitor as soon as possible after legal aid has been granted-unless the case is obvious - so that he or she may act as adviser or arbiter.

(3) Consent forms should be extended and made more informative, although not like the informed consent forms used in the
United States which may list every common and rare complication to protect the doctor. ${ }^{5} \mathrm{~A}$ middle way would be to document, for example, postoperative complications which can occur however perfectly an operation is performed: slight wound infection, a haematoma that might require the patient to be off work longer than expected, and the occasional reaction to a nylon suture. Stating on the consent form the fact that sterilisation carries a slight failure rate has already reduced the number of actions arising from this.

Risks and complications, perhaps placed at the bottom of the consent form and in small print, can be put into perspective and written in a reassuring way, if possible giving an approximate risk level, such as that wound infection occurs in three of 100 operations and a serious risk of a drug reaction is one in $\mathbf{4 0 0 0 0}$ patients. Such risk levels might be related to those accepted in everyday life. Much interest is being taken in clinical risks, and data might be obtained

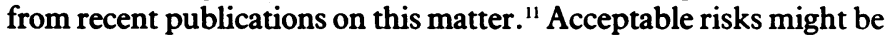
agreed on by a consensus achieved perhaps at a conference or from a working party, although complications are usually listed in current textbooks. This type of consent form would also provide the courts with written evidence of the information available for the patient and act as a safety net for the doctor, though with no guarantee against a successful legal outcome for the plaintiff. Consent forms and information leaflets, however, only complement communication and recording counselling consultations in the case notes.

This is a good time to consider the provision of information for patients, for the law concerning medical negligence may change. ${ }^{12}$ Lord Scarman, in the Sidaway case, ${ }^{13}$ showed some support for the doctrine in the United States of informed consent, stating that, whereas the Bolam principle (when doctors cannot be found negligent if they can show that they were following current medical practice ${ }^{14}$ ) might apply to diagnosis and treatment it should not apply to whether a doctor has given insufficient advice about the risks of a proposed treatment: that should be decided by the courts. And in 1986, during a court case concerning a child who died after external carotid embolisation it was stated that parents must be given enough information about the hazards of a treatment to form a balanced judgment before giving consent. ${ }^{15}$

Each year brings new medicolegal problems, and since this investigation was completed actions have arisen concerning, for example, failure to diagnose legionnaires' disease and alleged damage to the fetus from amniocentesis. So trends in the West Midlands region will continue to be monitored in the hope that such knowledge may help to warn of current risks.

\section{References}

1 Havard J. Americans still struggling with malpractice. $B r$ Med f 1987;295:399-400.

2 Smith R. When things go wrong-again. Br Med f 1987;295:621.

3 West Midlands Regional Health Authority. Facts and figures. Birmingham B16 9PA: West Midlands RHA, 146 Hagley Road, 1987.

Midlands RHA, 146 Hagley Road, 1987.
Action for the Victims of Medical Accidents. Annual report 1984-85. London: AVMA, 1986. 4 Action for the Victims of Medical Accidents. Annual report 1984-85. Lo

6 Elstein M. Containment of litigation in obstetrics and gynaecology: prevention. Journal of the Medical Defence Union 1987;3:19-20.

7 Allsopp KM. Saying sorry. Foumal of the Medical Defence Union 1986;2:2.

8 Weed LL. Medical records, medical education and patient care: the problem-orientated record as a basic cool. Cleveland, Ohio: Case Western Reserve University Press, 1969.

9 Quam L, Fenn P, Dingwell R. Medical malpractice in perspective. II-The implications for Britain. BrMed f 1987;294:1597-600.

10 Somers HL. The malpractice controversy and quality of patient care. Milbank Mem Fund $Q$ 1977;55:193-232.

11 O'Brien B. "What are my chances doctor?" A review of clinical risks. London: Office of Health Brien B. "What are my chances doctor?" A review of clinical risks. London:

2 Mason JK, Smith McCall RA. Law and medical ethics. London: Butterworths, 1987.

12 Mason JK, Smith McCall RA. Law and medical ethics

14 Bolam v Frien Hospital Management Committee. All England Law Reports 1957;2:118-28.

15 Dyer C. Death from interventionist radiology: a cautionary tale. Br Med J 1986;293:686-7.

(Accepted 27 October 1987) 